\title{
Occupational therapy graduates' reflections on their ability to cope with primary healthcare and rural practice during community service
}

\author{
Deshini Naidoo, B Occ Ther (UDW), M Occ Ther (UKZN), PhD Occupational therapy (UKZN) \\ Lecturer, Discipline of Occupational Therapy, School of Health Sciences, University of Kwa-Zulu Natal
}

\author{
Jacqueline Van Wyk, PhD Education (UKZN) \\ Educationalist, School of Clinical Medicine, University of KwaZulu Natal
}

Firdouza Waggie, PhD Education, (UWC)

Head of Interdisciplinary Teaching and Learning Unit, University of Western Cape

Background: Occupational therapy graduates are expected to deliver service in public health facilities using a primary healthcare approach (PHC) during their community service year. There is limited literature available about their experiences in this context.

Objective: This study explored the experiences of novice occupational therapy graduates and the extent to which their curriculum had prepared them for practice in PHC settings.

Methods: This qualitative exploratory study used purposive sampling to recruit thirty nine novice occupational therapy graduates. Using audio-recorded semi-structured interviews and a focus group discussion data were collected to explore participants' experience of work and the extent to which their undergraduate programme had prepared them for primary healthcare practice. The data was analyzed thematically.

Findings: Occupational therapy graduates expressed challenges in applying the PHC approaches for practice in resource-restricted rural settings. They required additional skills to communicate in the local indigenous language, to understand the various beliefs of the local communities and to manage change in these settings. They were well prepared for basic clinical skills as a need for urban-based ethical practice.

Relevance to clinical practice: Curriculum planners need to review the teaching of communication skills and introduce students to strategies for change management. More inter-professional collaboration and service-learning in rural primary healthcare settings will prepare them better for rural and PHC settings.

Key words: Occupational therapy education, Primary health care, rural practice , community service

\section{INTRODUCTION}

Health reform in post-apartheid South Africa (SA) has been geared to improve health outcomes and rectify historical inequalities ${ }^{1,2}$. The majority of the SA population (70\%) generally access the public health system while only $18,4 \%$, with medical insurance, access the much better resourced-private healthcare system ${ }^{3}$. The district health system facilitates the delivery of services in the public sector through geographically-zoned districts where services are offered at quaternary, tertiary, secondary, district and primary levels ${ }^{4}$. Factors such as the burden of disease, trauma and violence led to the implementation of the National Health Insurance (NHI) by the Department of Health $(\mathrm{DoH})$ to ensure greater access to health ${ }^{5-6}$. The primary healthcare (PHC) plan acknowledges "health care as a universal right, encompassing the promotion of healthy living, early disease detection, prevention and treatment, community-based disease management and rehabilitation"6:1. The re-engineered $\mathrm{PHC}$ plan is key to the success of the $\mathrm{NHI}^{7}$. Occupational therapists form part of the multi-disciplinary teams that provide rehabilitative, preventative and promotive programmes in hospital and community settings. Despite the positive intent of the health policies, implementation at grass-roots level remains a problem. A key challenge for occupational therapy relates to an expectation that they offer services at community - and primary health care (PHC) clinics, in addition to those already being rendered at the district hospital level ${ }^{8}$.
All SA-trained health care practitioners (HCP) offer a mandatory year-long community service following their graduation'. New occupational therapy graduates select a location for community service placement during their final year as a student. Community service is generally offered at a public, district health facility in a disadvantaged/rural community ${ }^{9}$. Community service thus provides recent graduates with opportunities to deliver culturally relevant services to disadvantaged communities in resource constrained settings ${ }^{10-11}$.

The occupational therapy programme offered at the University of KwaZulu-Natal (UKZN) offers a four year professional qualification. The curriculum is built on five main pillars namely occupational therapy, theoretical constructs and ethical practice, occupational therapy professional practice (techniques), service learning rotations (students deliver services during six to eight week blocks) in an acute hospital or non-governmental organisation setting and research. Students form part of a multidisciplinary team and work with stakeholders in community settings during a community service learning rotation. This engagement in inter-professional learning is essential as it develops students' skills in assessing clients, prioritising needs and intervention and collaborating with team members and intersectoral stakeholders ${ }^{12}$. UKZN has introduced a competency-based framework to develop appropriately competent health professions graduates $^{13}$. The framework proposes the acquisition of seven key roles including those of practitioner, communicator, collaborator, leader and manager, scholar, health advocate and professional ${ }^{13}$. 
During the community service year, a novice UKZN occupational therapy graduate has to apply $\mathrm{PHC}$ principles and approaches when offering services ${ }^{14}$. These recent graduates in $\mathrm{KZN}$, are often the only occupational therapist in the setting and are expected to spend $40 \%$ of their time in the community ${ }^{14}$. This has led to a shift to ensure that novice health professionals are competent to deliver relevant and appropriate services to underserved communities in the SA context. There is however limited literature available in the SA context on the experiences of novice occupational therapy graduates during their community service year. This paper describes a study that explored the working experiences of novice occupational therapy graduates in rural and peri-urban settings during community service, while following a PHC approach.

\section{LITERATURE REVIEW}

Occupational therapy practice and education in SA has been influenced by four main organisations, namely the global regulatory body - the World Federation of Occupational Therapy (WFOT); the national professional body the Occupational Therapy Association of South Africa (OTASA); the national professional regulatory body the Health Professions Council of South Africa (HPCSA); and the South Africa Qualifications Authority (SAQA) which recognises the institutional formal qualification. WFOT's minimum standards for occupational therapy training ${ }^{15}$ advises occupational therapy educators to consider curricula that include population-based approaches to therapy, health promotion and disease prevention ${ }^{15}$. Educational programmes should also instil social accountability and skills in graduates to identify and act when encountering issues relating to occupational injustice during community practice ${ }^{15}$. OTASA has furthermore challenged occupational therapy educators to include managerial and practice skills in occupational therapy programmes to prepare graduates for planning and service delivery in complex new environments ${ }^{16}$. The HPCSA similarly has set minimum standards for occupational therapy-training ${ }^{17}$ and SAQA has specified exit-level outcomes for occupational therapy qualifications ${ }^{18}$. While many publications describe the experiences of the community service doctors ${ }^{19,20}$, little is known about the experiences of allied health professionals $^{11,21}$. The experiences of the SA occupational therapy community service practitioners and the suitability of educational programmes for $\mathrm{PHC}$ practice in the rural and peri-urban context has also not yet been explored.

In addressing the educational needs of the healthcare professions for the $21^{\text {st }}$ century, Frenk et al. re-iterated the need for institutional and instructional changes to equip graduates with technical competencies, critical reasoning, ethical conduct and social attributes and become advocates for their clients ${ }^{22}$. In this way, Frenk et al. ${ }^{22}$ have added to the global debate for graduates to address the challenges in health-outcomes at community level. Several authors suggest the use of transformative learning approaches to promote the acquisition of ethical and socially accountable practice ${ }^{23-25}$. Mezirow's use of critical reflection is also advocated as a possible strategy to foster the development of new concepts ${ }^{26}$. Additionally, rational discourse which challenges students' assumptions and facilitates their reasoning though decisions, is suggested to promote students' professional reasoning and practice ${ }^{25-26}$.

There are increased debates regarding the relevant education and training offered by Higher Education Institutions (HEI) in SA to equip students for practice in the current health system and the African context ${ }^{27-29}$. Currently students develop professional practice skills predominantly during service learning in hospitals, school settings or NGOs. Despite some community-based service learning exposures, anecdotal evidence indicates that students still learn predominantly in well-resourced urban hospitals. While an individualised, hospital-based approach to therapy remains necessary, the use of alternative service learning placements to develop a population-focused therapeutic approach in graduates, is not sufficiently being explored. This shift in focus is necessary especially in the light of the $\mathrm{NHI}$ implementation. There is limited literature on how novice occupational therapy graduates translate their undergraduate propositional knowledge into practice during their community service.

\section{METHOD}

\section{Study design}

This study used an interpretivist social - constructivism paradigm to explore the experiences of the South African novice occupational therapy graduates during their community service ${ }^{30-31}$. The interpretivist social - constructivism view allowed for a focus on the meaning derived from participants' socially constructed experiences of working during community service. The explorative qualitative design allowed the use of multiple data gathering methods namely semi-structured interviews, focus group discussions and field observations to obtain rich data on the topic and ensure data triangulation ${ }^{30-31}$.

\section{Study setting and Participants}

The study was conducted in KwaZulu-Natal (KZN) as occupational therapy graduates from the institution predominantly complete their community service in KZN public health facilities. In addition, the UKZN has a memorandum of understanding with KZN-DoH to accommodate the health service education of its students.

All graduates who had practiced occupational therapy for three years or less were considered novice occupational therapists. UKZN occupational therapy graduates from the 20I3, 20I4 and 20 I 5 cohorts $(N=70)$ who had completed community service in $\mathrm{KZN}$, received email invitations to participate in the study. Of these, 39 novice occupational therapy graduates agreed to participate. The three cohorts of graduates had all provided services at PHC clinics during their community service.

\section{Data Collection}

The data were collected through semi-structured interviews and a focus group as well as field observations. The audio-recorded interviews were 45 to 70 minutes in duration and occurred either face to face or via the telephone depending on the preference of participants and were conducted by the researcher. The schedule of open-ended questions for the semi-structured interviews explored the participants' experience of working in the public health sector, type of services they currently offered, how they incorporated a $\mathrm{PHC}$ approach into their occupational therapy practice and their perceptions around how the undergraduate training prepared them for practice during their community service year. A focus group was held with a group of nine occupational therapy graduates. During the focus group the participants related their experiences of working and responded to questions based on themes that emerged from the semi-structured interviews. This allowed the researcher to explore the challenges experienced by participants and the strengths of the occupational therapy programme. Field observations included shadowing of two community service occupational therapists who worked in peri-urban and rural districts. The researcher observed these therapists in the hospital, while they worked at the clinic and in the community when they conducted home visits to facilitate a greater understanding of the realities of working in a PHC context.

\section{Data Analysis and Trustworthiness}

The audio-recorded semi-structured interviews and focus group discussions were transcribed verbatim by a research assistant and cross referenced against field notes taken by the researcher. The data was thematically analysed ${ }^{30}$. The printed transcripts were read and reread to gain familiarity with the data. Thereafter initial codes were assigned. The initial codes were combined to form categories during a second level of analysis. This formed the subthemes. The researcher searched for similarities and differences in the categories/subthemes to allow for the organisation of related categories into an overall theme. A co-researcher reviewed the codes and themes and ensured that all data were included. 
Rigour was established through data triangulation. The veracity of the data was checked through presenting a summary of the key points at the end of each interview or focus group and verifying whether this was a true reflection of the participants' responses. Prior to commencing the study the researcher wrote a reflexive statement about her personal values, areas she was subjective about and the potential power relations between her and the participants in order to bracket potential bias. This was necessary as the principal researcher is a lecturer in occupational therapy at UKZN. Data were collected until redundancy was achieved. Finally, confirmability was ensured through the use of an audit trail.

\section{Ethical approval and consent}

Ethical approval was obtained from the Biomedical Research Ethics Committee (ethics number BE 248/I4). Permission for the study was obtained from the district managers at the various sites and the KwaZulu-Natal Provincial ethics committee. All participants signed a consent form and were informed of their right to withdraw. Pseudonyms were used to ensure confidentiality and anonymity.

\section{Limitations of the study}

All the participants were graduates from UKZN thus limiting generalizability of the findings. The researcher is embedded within the UKZN programme which served to enhance the understanding of the context however may have influenced participants' responses. It would have been beneficial to explore other DoH employees' perspectives to better understand the service required in the public health sector.

\section{FINDINGS}

\section{Demographics of the participants}

The sample (39) consisted predominantly of females $(n=37)$ with only two male participants $(n=2)$ having graduated from the UKZN occupational therapy programme. Nineteen participants were White, eleven were Indian, five were Black and four were Coloured. The ages of participants ranged from 23 to 36 years. At the time of the study, the participants from the 2013 and 2014 cohorts had started work and reported on their experiences of community service while the 2015 cohort were undergoing their community service. Despite this difference, the successes and challenges reported by these cohorts revealed similar themes. All participants completed their community service in public district hospitals and community healthcare centres in rural and peri-urban districts of $\mathrm{KZN}$. They mainly rendered occupational therapy services to inand out-patients at rural hospitals on a two to three day a week basis. Twice a week, they offered the same services to PHC clinics located approximately 50 to $300 \mathrm{~km}$ (I to 3 hours travel time) from their assigned hospital.

\section{Themes}

Two main themes emerged in response to questions that explored the novice occupational therapy graduates' experiences of working during their community service and whether they had translated their theoretical knowledge on PHC into practice. The first theme is in relation to the challenges experienced by participants and the second relates to the strengths of the occupational therapy programme and how it had prepared them for PHC practice. See Table $I$ (page 42) and Table 2 (page 42) for an overview of the themes and relevant quotations.

\section{Theme one: Challenges experienced by novice occupational therapy graduates}

This theme outlined the challenges that the participants experienced while implementing PHC approach in a rural setting. Subsequently, four subthemes emerged namely challenges due to practice in a rural setting, communication and change management, collaboration and cultural sensitivity and the challenges due to the occupational therapy curriculum (See Table I).
Subtheme One: Challenges due to Practice in a Rural Setting

Participants reported feeling unprepared for practice in the rural setting. They were challenged by the realities of practicing in rural, resource constrained environments as their undergraduate programme and clinical skills development had happened mainly in well-equipped tertiary hospitals. Additionally, they were unaccustomed to the conditions and injuries in the rural clinics which were mainly due to injuries caused by incidences of violence. The participants articulated the need to better understand and implement a PHC approach in a clinic. Participants experienced pressure as they were required to work at a much faster pace as practitioners as compared to service learning.

Subtheme two: Communication and Change management

Participants reported an inability to communicate effectively with service-users, team members and hospital management. Their difficulties in communication mainly occurred where the language of service users differed from their own. The participants needed the ability to talk to and know how to approach people in a suitably respectful way especially with service-users and other staff. Participants were also enthusiastic about negotiating change in the workplace, but they faced challenges when trying to implement the changes. In some cases it led to conflict which demotivated them from becoming more involved.

Subtheme three: Collaboration and Cultural sensitivity The participants identified a need to improve their cultural sensitivity. They articulated that having greater skills in cultural sensitivity in the workplace would improve their ability to collaborate with others on the healthcare team. Participants expressed the need for improved insight into the norms, values and belief systems of their service-users. They thought that an improved understanding of the cultural nuances of the communities where they worked would be beneficial. They also required greater understanding of how the context and culture influenced the service- users' participation in daily activities. Participants became aware of their ethnocentric beliefs and the possible impact of these beliefs on how they delivered services. Finally, the participants reported experiencing difficulty in translating their understanding of their profession in a way that merged with the culture of the population they were serving.

\section{Subtheme Four: Challenges due to the Occupational} Therapy Curriculum

Participants voiced concern at the inadequate exposure to preventive and promotive therapy during their undergraduate programme. Participants reported that their daily practice had required the ability to shift their professional focus and reasoning between treatment given to children and adults throughout the day. Exposure during service learning placements traditionally focussed only on one age group or a category of diagnosis such as a physical condition. Participants were also not adequately prepared for the reality and impact relating to hospital politics. They articulated that the lack of exposure to inter-professional education and teamwork resulted in misconceptions around the roles of various health professions' stakeholders. The participants thought that their undergraduate programme should include procedures relating to government departments, new health care policies and procedures for referral within the $\mathrm{DoH}$. They also lacked exposure and confidence relating to the expected administrative duties as an occupational therapist.

\section{Theme Two: Strengths of the UKZN Occupational Therapy Programme}

\section{Subtheme I: Strengths in the Curriculum}

The occupational therapy curriculum reportedly had equipped participants with adequate theoretical knowledge and basic clinical skills to implement remedial and rehabilitation hospital-based 
Table I: Overview of Challenges experienced

Theme one: Challenges experienced by novice occupational therapy graduates

\begin{tabular}{|c|c|c|}
\hline Subthemes & Descriptive Codes & Evidence \\
\hline $\begin{array}{l}\text { I. Challenges due to } \\
\text { practice in rural } \\
\text { settings }\end{array}$ & $\begin{array}{l}\text { Unprepared for rural context. } \\
\text { Decreased understanding the PHC approach. } \\
\text { Lacked exposure to primary healthcare clinic. } \\
\text { Unaware of the realities of practicing in a rural resource } \\
\text { constrained environment. }\end{array}$ & $\begin{array}{l}\text { The rural aspect of it, the language barrier aspect of it, } \\
\text { the lack of resource aspect of it, I was not prepared for } \\
\text { that. Semi structured interview with T. } \\
\text { We need more clinic experience. Because I shied } \\
\text { away in the beginning I must be honest, my comm. } \\
\text { serve year because I was like scared. Semi structured } \\
\text { interview with B. }\end{array}$ \\
\hline $\begin{array}{l}\text { 2. Communication and } \\
\text { change management }\end{array}$ & $\begin{array}{l}\text { Experienced obstacles when communicating with a patient } \\
\text { who spoke in another language e.g. IsiZulu. } \\
\text { Needed to have better understanding regarding a } \\
\text { respectful way to communicate with patients and their } \\
\text { families and staff. } \\
\text { Challenges experienced when implementing change. }\end{array}$ & $\begin{array}{l}\text {...how to talk to and how to approach people ... } \\
\text { because you are young, which in the community was } \\
\text { also a bit of difference, ... I was } 22 \text { on comm. service, } \\
\text { I was an outsider, ... Semi structured interview with } \\
\text { A. } \\
\text {... and people might find us argumentative, but the } \\
\text { thing is we just want to defy stereotypes, physical and } \\
\text { social barriers... but they obviously see it as us pushing. } \\
\text { Semi-structured interview with N. }\end{array}$ \\
\hline $\begin{array}{l}\text { 3. Collaboration and } \\
\text { Cultural sensitivity }\end{array}$ & $\begin{array}{l}\text { Challenges with cultural sensitivity need to improve their } \\
\text { insight and understanding of the norms, values and belief } \\
\text { systems of the service users and the influence of context } \\
\text { and culture on the daily activities of the service-users. } \\
\text { * Need to adapt to the organisational culture i.e. protocols } \\
\text { and expected behaviours in the hospital and clinics. } \\
\text { Explaining professional in a culturally relevant manner. }\end{array}$ & $\begin{array}{l}\text {...you have to learn to deal with different cultures... } \\
\text { Trying to break barriers because I was this white girl. } \\
\text { Semi structured interview with V. } \\
\text { The cultural differences with the staff were one of the } \\
\text { biggest challenges for me. So how to speak to your } \\
\text { hospital manager who is more than twice your age } \\
\text { and of a completely different culture. Semi structured } \\
\text { interview with G. } \\
\text {...you come with the OT concepts it sounds like an } \\
\text { urban profession which is not known in the African } \\
\text { culture. Semi structured interview with P. }\end{array}$ \\
\hline $\begin{array}{l}\text { 4. Challenges due } \\
\text { to the occupational } \\
\text { therapy curriculum }\end{array}$ & $\begin{array}{l}\text { Mostly Remedial, hospital -based rehabilitation taught } \\
\text { rather than PHC. Need for health prevention and } \\
\text { promotion. } \\
\text { - Service learning rotations orientated to physical } \\
\text { psychiatryor paediatrics. Difficulty shifting } \\
\text { professionalfocus and reasoning between children and } \\
\text { adults. } \\
\text { - Inadequate inter-professional education. } \\
\text { Needed to know procedures of other government } \\
\text { departments, new health care policies, how networks } \\
\text { within the DoH operated to secure resources. } \\
\text { Needed to be prepared for administrative tasks. }\end{array}$ & $\begin{array}{l}\text { I was not prepared to understand the politics in the } \\
\text { hospital ... you are never forced to work with a physio } \\
\text { at a hospital level. Semi- structured interview with B. } \\
\ldots \text { I would treat a kid and then an adult and I found } \\
\text { it difficult to adjust to that type of planning. (Semi } \\
\text { structured interview with N. } \\
\text { Not knowing the polices and how the system works } \\
\text { like those were the barriers. Semi structured } \\
\text { interview with L. }\end{array}$ \\
\hline
\end{tabular}

Table 2: Overview of Strengths of the UKZN OT programme Theme two: Strengths of the UKZN Occupational Therapy programme

\begin{tabular}{|c|c|c|}
\hline Subthemes & Descriptive Codes & Evidence \\
\hline $\begin{array}{l}\text { I. Strengths within } \\
\text { curriculum. }\end{array}$ & $\begin{array}{l}\text { Well prepared for hospital based practice. } \\
\text { Good ethical grounding for practice. } \\
\text { Community rehabilitation modules were beneficial. }\end{array}$ & $\begin{array}{l}\text { Felt prepared for OT in a hospital setting. Semi structured } \\
\text { interview. } \\
\text { that [community based rehabilitation] module was good } \\
\text { in the sense that you had to go out to the community and } \\
\text { work with the community leaders and stuff like that. Semi } \\
\text { structured interview, with D. }\end{array}$ \\
\hline $\begin{array}{l}\text { 2. Positive contributions to } \\
\text { the workplace. }\end{array}$ & $\begin{array}{l}\text { Motivated for work and feeling rewarded when } \\
\text { witnessing the impact of their interventions in the } \\
\text { lives of their patients. } \\
\text { Collaborations with hospital staff led to } \\
\text { improvements in services at the hospitals. }\end{array}$ & $\begin{array}{l}\text {...actually working with the patients like people who really } \\
\text { need you and if you are not there, there is no one else and } \\
\text { there will be nothing else for them. So in that way it was } \\
\text { very rewarding. Semi- structured interview with G. } \\
\text { I established a cerebral palsy group that was run by } \\
\text { occupational therapy and eventually I got the MDT team on } \\
\text { board, that was the biggest success at the hospital for the } \\
\text { year. Semi structured with J. }\end{array}$ \\
\hline
\end{tabular}


interventions. The service-learning blocks created a suitable environment where they practiced and applied the acquired theoretical principles. The community rehabilitation modules offered participants sufficient opportunity to interact with members from urban communities. The programme also equipped participants with skills needed for research and participants valued the ability to access and retrieve literature to solve problems in their practice settings. Another strength noted was the strong orientation to ethical practice within the curriculum. (See Table 2 on page 42)

Subtheme 2: Positive Contributions to the Workplace Overall participants reported being motivated to practice as occupational therapists. They expressed satisfaction when witnessing the impact of their interventions in the lives of the service- users. Their collaborations with hospital staff also led to improvements in services at the hospitals.

\section{DISCUSSION}

The findings created insight into the challenges experienced by novice graduates' experience in applying PHC approaches for practice in resource-restricted rural settings. Since the newly qualified participants were mostly White and Indian occupational therapists, it was foreseeable that their difficulties would include both challenges with language and cultural nuances when working in rural settings of KwaZulu-Natal. However, the reported challenges of graduates suggest the need to review the curriculum and its associated teaching and learning strategies. The curriculum thus needs to include exposure to equip graduates to address issues of health and occupation within communities. These findings concur with literature indicating the preferences of graduates to practice in settings that resemble their training environments $\mathrm{s}^{32,33,34}$.

Being unprepared for the rural context and the realities of practicing in rural resource constrained environments was one of the main challenges. The students' limited understanding to implement a PHC approach and inadequate exposure to practicing in $\mathrm{PHC}$ clinics restricted their ability to cope in this context. Several authors have written about the need to review service learning placements $^{33,34}$. Janse Van Rensburg and Du Toit suggest that rural service learning placements offer an opportunity to prepare students for the dynamics of working in rural community settings ${ }^{33}$. They also argue that the autonomy acquired in rural settings allows greater personal growth and that it increases students' ability to solve professional practice problems ${ }^{33}$. Rural placement also offers opportunities to students to understand the realities- and to practice a PHC approach in the South African setting ${ }^{33,34}$.

Participants reported significant challenges in communicating with service users, managers and other members of health professions' teams. UKZN already offer programmes in communication skills in the College of Health Sciences at UKZN ${ }^{35}$. The communication programme offered in health science is currently only offered in the first year and applied in clinical settings thereafter ${ }^{35}$. There is a need to investigate how the curriculum can foster the development of communication skills to interact with patients of different cultures, communicate with team members and with hospital management.

The participants experienced difficulty with managing and implementing change and advocating for service-users. The resultant conflict or negative experiences left the participants demotivated. Difficulty with implementing change management may stem from participants' struggle with challenging the existing medical model as driven by hospital- based protocols ${ }^{36}$. Methot ${ }^{37}$ similarly found that the dominant medical discourse in hospital practice hindered therapists' ability to implement programmes that promote health and prevent disability. Pollard, Sakellariou, and Kronenburg highlighted the need for occupational therapy students to recognise the political nature of their roles as advocates and change agents ${ }^{38}$. The inclusion and use of transformative learning during service learning rotations, has been advocated to develop students' leadership- and change management abilities ${ }^{22}$.
Acknowledging cultures and being culturally sensitive is essential for health professional practice ${ }^{39,40}$. Participants identified a need to understand the cultural nuances of particular communities where they worked and the influence of context and culture on the daily activities of the service users. They also struggled with adapting to the expectations of hospital staff where the organisational culture differed from their personal worldviews. Culturally competent healthcare delivery would thus require more than acknowledgement of the culture of each ethnic group but also the ability to think and behave in ways to facilitate effective cross-cultural interactions $^{41}$. The curriculum should thus create awareness of students' own cultural values and ethnocentric interpretations and respect for those of others. They also should examine the influence of culture on their professional values, communication and social behaviour ${ }^{40,41}$

Working as part of a multidisciplinary team and communication within the team was challenging for graduates as they did not train in inter-professional teams. The shortage of health professionals in the South African rural communities necessitates the use of a multidisciplinary approach and co-ordinating community focused goals rather than becoming engaged in disputes over professional boundaries ${ }^{42}$. Development of inter-professional learning and collaboration of health professions during service learning placements would provide the opportunity for students to discover the scope and practice skills of other allied disciplines ${ }^{12,42}$. In addition it would promote greater understanding of each profession's role in the team $^{12,42}$.

Challenges experienced due to the curriculum included being exposed to mainly remedial hospital -based rehabilitation, restricting the diagnostic or age group of service users that the participants need to focus during service learning rotations and limiting the workload. Also a lack in understanding procedures of other government departments, how networks within the DoH operated to secure resources and how to perform administrative tasks were noted. Graduates needed an awareness of the organisation of the health system, the governmental health priorities and the suggested approach to be followed (primary healthcare reengineering) to ensure efficient service delivery. Awareness of health policies and human rights are also required to advocate for patients and support occupational justice in healthcare ${ }^{38,43}$.

Several strengths of the curriculum were highlighted in the findings. Participants were prepared for practice in urban hospital and urban community settings. They perceived they were well prepared for clinical reasoning in urban settings. Scholars agree that students benefit from having a repertoire of scenarios to use as foundation for future interventions and to improve their ability to be flexible to alter and adapt their intervention plans ${ }^{32,44}$. The ability to research intervention strategies and apply problem-solving strategies was another strength noted. The ability to research and contextualise evidence as expected in the professional context highlights that novice occupational therapy graduates were developing the researcher role as outlined in the UKZN competency framework ${ }^{13}$.

Of interest was the mention of the strong focus on ethical practice and the commitment to provide appropriate interventions for the service-users. This demonstrates the positive influence of the curriculum on graduates' sense of social accountability and the resultant desire to ensure effective practice, which resonates with the competencies required by practitioner and professional role in the UKZN competency framework ${ }^{13}$.

Evidence from this study has a number of implications for curriculum review. Findings of being unprepared due to a lack of exposure to the PHC approach in resource constrained settings are not unique to this study. Health educators have been advised to interrogate the curriculum to ensure that graduates are suitably prepared to function in rural practice ${ }^{33,34,45}$. We are reminded that there is a need for new models of curriculum to prepare graduates adequately for community service in the South African context ${ }^{10,11}$.

A recurring theme from the literature was the need to review instructional practices especially in the service-learning placement 
context to improve the match of the training environment and the intended context of practice ${ }^{34,46}$. The inclusion of rural communitybased service learning placements is believed to provide a transformative learning experience to guide students' clinical reasoning and $\mathrm{PHC}$ practice experiences for effective work in rural contexts $\mathrm{s}^{33,34,46}$. The benefits of community-based rural education include students being placed in rural and peri-urban sites; exposure to different levels of care and facilitating a greater understanding of the contextual and social factors that influence health ${ }^{33,34,46}$. Rural community-based service-learning has several benefits which include student exposure to different service- user populations, the instilling of cultural sensitivity and understanding of the norms and traditions of the community and understanding the dynamics of working in a rural area $^{33,34,46}$. Successful rural placement requires curricular revision of the service learning component to include specific learning outcomes, structured learning activities and a review of associated assessment strategies e.g. use of critical incidents, use of portfolios etc. Furthermore, teaching and learning strategies that promote critical reflection on practice should be incorporated to facilitate transformative learning experiences. These learning experiences should promote a shift from hospital and urban based interventions to population-based primary healthcare approaches to allow exposure to home-based interventions in resource-constrained clinical and community based settings. Additionally, students need to learn how to be resourceful and use resources from the community to make simple inexpensive equipment and assistive devices for training caregivers and family members.

\section{CONCLUSION}

This paper has provided useful insights into novice occupational therapy graduates' experiences in rural KZN settings during their community service year. The highlighted challenges have provided a focus for curriculum revision and lessons to improve graduate preparation. It is essential to review current practices and communication teaching to address challenges in communication and cultural competence. Further implications relate to a need for change management strategies and opportunities for learners to engage in inter-professional collaboration and to practice creative and resourceful intervention strategies during service learning in rural primary care settings.

Further research of stakeholders' perceptions of the role of occupational therapy in primary health care would be beneficial to clarify service delivery outcomes needed and the competencies required for practice. This would allow curriculum planners to contextualise the occupational therapy programme and the graduate competencies for practice within the public sector and changing South African healthcare.

\section{REFERENCE LIST}

I. Mayosi BM, Lawn JE, Van Niekerk A, Bradshaw D, Karim SSA, Coovadia HM, team LSA. Health in South Africa: Changes and Challenges since 2009. The Lancet 20I2; 380 (9858): 2029-2043.

2. Statistics South Africa. House hold survey 2013 . Available at: http:// www.statssa.gov.za/publications/P03 18/P03 182013.pdf. (Accessed 26 June 2016).

3. South African Government. The National health Act no $6 \mathrm{I}$ of 2003. Available at: https://www.acts.co.za/national-helth-act-2003/index. html. (Accessed 26 June 20l6).

4. Dhai A. Healthcare Reform in South Africa: A Step in the Direction of Social Justice. South African Journal of Bioethics and Law. 20I I; 4 (2): 48-49.

5. South African Government. National health insurance green paper. 201 I. http://www.gov.za/sites/www.gov.za/files/nationalhealthinsurance_2.pdf. (Accessed 28 June 2016)

6. South African Government. The national health insurance white paper. 20I5. Available at: http://www.gov.za/sites/www.gov.za/ files/National Health Insurance White Paper IODec2015.pdf. (Accessed 26 June 2016).

7. Pillay $\mathrm{Y}$, Barron P. Provincial guidelines for the implementation of the three streams of PHC re-engineering [serial online]. 2012 [cited 2015 Dec 23]. Available from: https://www.phasa.org.za/ wp-content/uploads/20I I/I I Pillay-Theimplementation-of-PHC.pdf.

8. Bateman C. 'One size fits all' health policies crippling rural rehab: therapists. South African Medical Journal. 2012; 102(4): 200-8.

9. Health Professions Council of South Africa: Health Professions Act 56 of 1974 Regulations Relating To Performance Of Community Service By Persons Registering In Terms Of The Health Professions Act, 1974. 2002. Available at: http://www.hpcsa.co.za/Content/ Docs/regulation_gnr688_98.pdf. (Accessed 26 June 2016)

10. Burch V, Reid S. Fit for Purpose? The Appropriate Education of Health Professionals in South Africa. South African Medical Journal 20II; I0I (I): 25-26.

II. Mostert-Wentzel K, Frantz J, Van Rooijen AJ. A model for community physiotherapy from the perspective of newly graduated physiotherapists as a guide to curriculum revision. African Journal of Health Professions Education. 2013; 5(I): 19-25.

12. Mpofu R, Daniels PS, Adonis T-A, Karuguti WM. Impact of an interprofessional education program on developing skilled graduates well-equipped to practise in rural and underserved areas. Rural and Remote Health. 2014; 14: 2671.

13. University of KwaZulu-Natal. Core Competencies for Undergraduate Students in the College of Health Sciences. 20I4/I5.

14. KwaZulu Natal Department of Health (20I0) Policy Community Service Officers.

15. World Federation of Occupational therapists. Revised Minimum Standards for The Education of Occupational Therapists working draft V. 20I5. Council of the World Federation of Occupational therapists.

16. Occupational Therapy Association of South Africa. Position Statement on Occupational Therapy in Primary Health Care. South African Journal of Occupational therapy. 2015; 45(3): 58-59.

17. Health Professions Council South Africa. Minimum standards of training for Occupational therapists; 2009.

18. South African Qualification Authority. Professional Board for Occupational Therapy, Medical Orthotics/Prosthetics and Arts Therapy Submission of a Qualification For Registration with SAQA; 2006.

19. Reid S, Conco, D Varkey, SJ Fonn S. Monitoring the implementation of community service. South African Health Review. 1999; 233-248. http://www.healthlink.org.za/uploads/files/chapter 17 99.pdf. (Accessed 26 April 2016)

20. Van Niekerk, JP. Internship and community service require revision. South African Medical Journal. 2012; 102 (8): 638. http://dx.doi. org/I0.7196/SAM]. 6094.

21. Ramklass S. Physiotherapists in under-resourced South African communities reflect on practice. Health and Social Care in the Community. 2009; 17(5); 522-529.

22. Frenk J, Chen L, Bhutta Z, Cohen J, Crisp N, Evans T, Fineberg H, Garcia P, Ke Y, Kelley P, Kistnasamy B, Meleis A, Naylor D, PablosMendez A, Reddy S, Scrimshaw S, Sepulveda J, Serwadda D; Zurayk $\mathrm{H}$. Health professionals for a new century: transforming education to strengthen health systems in an interdependent world. Lancet; 2010; 376(9756): 1923-58.

23. Woollard B, Boelen C. Seeking impact of medical schools on health: meeting the challenges of social accountability. Medical Education. 20I2; 46(I): 21-27.

24. Boelen C., Woollard B. Social accountability: the extra leap to excellence for educational institutions. Medical Teacher. 20II; 33(8): 614-619.

25. Taylor EW. Transformative learning theory. New directions for adult and continuing education. 2008; I(II9): 5-I5.

26. Mezirow J. Transformative dimensions of adult learning. San Francisco: Jossey-Bass; 1991.

27. Watson R. Population based approach to occupational therapy. South African journal of occupational therapy 2013; 43(I): 34-39.

28. De Jongh J. An innovative curriculum change to enhance occupational therapy student practice. South African Journal of Occupational Therapy. 2009; 39(I): 31-38.

29. De Jongh J, Hess-April L, Wegner L. Curriculum transformation: a proposed route to reflect a political consciousness in occupational therapy education. South African Journal of Occupational Therapy. 2012; 42(I): 16-20.

30. Creswell JW. Qualitative Inquiry and Research Design Choosing among Five Approaches 3rd edition. Thousand Oaks: SAGE. 2013.

3I. Patton M Q. Qualitative Research and Evaluation Methods. 3 
ed.Thousand Oakes: SAGE. 2015.

32. Naidoo D, Van Wyk J, Joubert R. Are Final Year Occupational Therapy Students Adequately Prepared for Clinical Practice? A Case Study in Kwazulu-Natal. South African Journal of Occupational Therapy. 20I4; 44 (3): 24-28.

33. Janse van Rensburg E, Du Toit SH. The Value of a Rural Service Learning Experience for Final Year Undergraduate Occupational Therapy Students. South African Journal of Occupational Therapy. 2016; 46 (I): 9-14.

34. Van Schalkwyk S, Bezuidenhout J, Conradie H, Fish T, Kok N, Van Heerden B, De Villiers M. Going Rural': Driving Change through a Rural Medical Education Innovation. Rural and Remote Health. 20।4; I4 (2): 2493.

35. Matthews M, Van Wyk J. Speaking the Language of the Patient: Indigenous Language Policy and Practice. South African Family Practice. 20I5; 58 (I): 30-3I.

36. Wilding C. Raising Awareness of Hegemony in Occupational Therapy: The Value of Action Research for Improving Practice. Australian Occupational Therapy Journal. 201 I; 58 (4): 293-299.

37. Méthot D. Capacity and Competency, Collaboration and Communication: A Road Map for the Future. Canadian Journal of Occupational Therapy. 2004; 7 I (4): 197-198.

38. Pollard N, Kronenberg F. A Political Practice of Occupational Therapy E-Book. Elsevier Health Sciences; 2008.

39. Murden R, Norman A, Ross J, Sturdivant E, Kedia M, Shah S. Occupational Therapy Students' Perceptions of Their Cultural Awareness and Competency. Occupational Therapy International. 2008; I5 (3): 19|-203.

40. Rasmussen TM, Lloyd C, Wielandt T. Cultural Awareness among Queensland Undergraduate Occupational Therapy Students. Australian Occupational Therapy Journal. 2005; 52 (4): 302-310.

4I. Dupre AM, Goodgold S. Development of physical therapy student cultural competency through international community service. Journal of Cultural Diversity. 2007; I4(3): I26-34.

42. Bateman C. Multidisciplinary Teams-the Rural Way Forward. South African Medical Journal. 2008; 98 (I): 19-22.

43. London L, Baldwin-Ragaven L. Human Rights and Health: Challenges for Training Nurses in South Africa. Curationis. 2008; 3I (I): 5-I8.

44. Ajjawi R, Higgs J. Learning to Reason: A Journey of Professional Socialisation. Advances in Health Sciences Education. 2008; 13 (2): $133-150$

45. Hansen AMW, Muñoz J, Crist PA, Gupta J, Ideishi RI, Primeau LA, Tupé D. Service Learning: Meaningful, Community-Centered Professional Skill Development for Occupational Therapy Students. Occupational Therapy in Health Care. 2007; 2 I (I-2): 25-49.

46. Kaye DK, Muhwezi WW, Kasozi AN, Kijjambu S, Mbalinda SN, Okullo I, Nabirye RC, Oria H, Atuyambe L, Groves S. Lessons Learnt from Comprehensive Evaluation of Community-Based Education in Uganda: A Proposal for an Ideal Model Community-Based Education for Health Professional Training Institutions. BMC Medical Education. $201 \mathrm{I}$; II (I): 7.

\section{Corresponding Author}

\section{Deshini Naidoo}

Naidoodes@ukzn.ac.za

orcid.org/0000-000I-6276-22IX 